\title{
On the variability of aftershock ground motions in the San Fernando Valley
}

\author{
S. E. Hough \\ United States Geological Survey, Pasadena, California \\ C. Dietel, G. Glassmoyer, and E. Sembera \\ United States Geological Survey, Pasadena, California
}

\begin{abstract}
We analyze aftershocks of the 1/17/94 Mw6.7 Northridge earthquake recorded at a 3-element small-aperture array within the town of Northridge, above the mainshock rupture plane. Many of the M4-5 aftershocks are observed to have a prolonged shaking duration, up to $\mathbf{- 8}$ seconds, with conspicuous longer period $(\approx 1 \mathrm{~s})$ arrivals in the latter part of the wave train. Recordings of a M4.0 aftershock that occurred at 23:49 GMT on 1/17 show the origin of these waves. A slant-stack cross-correlation method on each of the three components shows that the late arrivals are characterized by low apparent velocities and a back-azimuth that is approximately 10 degrees off that of the direct arrivals. Based on the inferred apparent velocities and consideration of studies in other sedimentary basins, we conclude that these later arrivals consist of surface waves generated within the San Fernando Valley. Similar results are obtained for a M3.4 event recorded across the array. The surface waves are not, however, a ubiquitous feature of the aftershock recordings. We show that other $M^{\sim} 4$ events recorded at the same site are characterized by simple displacement pulses and durations that are typical for their magnitude, suggesting that 3-dimensional site response may be difficult to predict in cases where the sources are close to a valley or basin and/or the basin structure is complex.
\end{abstract}

\section{Introduction: Data}

The morning of the $M_{w} 6.7,1 / 17 / 94$ Northridge earthquake, we deployed 3 portable digital GEOS recorders (Borcherdt et al., 1985) in a small-aperture array configuration within the town of Northridge, a few kilometers north of the epicenter. Each site was instrumented with a 3-component Mark Products $\mathrm{L}-22 \mathrm{2}-\mathrm{Hz}$ sensor and and a Kinemetrics force-balance accelerometers (fba). The data are sampled at 100 samples per second on all channels.

The three stations comprising the array, MK1, MK2, and MK3, form a triangle roughly $200-250 \mathrm{~m}$ on each side. The array is situated within the San Fernando Valley (Figure 1). The deployment was motivated by the opportunity to obtain digital array recordings of moderate-to-large magnitude aftershocks at close epicentral distance to a large, denselypopulated valley.

The instruments remained deployed for the month beginning on 17:38 GMT on 1/17. Several hundred events (associated

This paper is not subject to U.S. copyright. Published in 1995 by the American Geophysical Union. with the Southern California Seismic Network, SCSN, catalog) were recorded on at least one station in this time; 49 events were recorded on all three stations. Several of the larger events cannot be used for array analysis because they occurred when only 2 of the fba's were operational (one of the fba's malfunctioned during the first two weeks of the deployment), and many of the remaining events were too small to produce enough long period energy to provide coherent signal across the array. We will focus on two events that are both well-recorded across the array and are large enough to generate relatively long-period waveforms: a M4.0 event at 23:49 GMT on 1/17 (Event 1), and a M3.4 event at 21:26 GMT on 1/21 (Event 2). We will also discuss other events that were well-recorded on one or two of the array stations.

\section{Analysis}

Figure 2 shows the NS component for the 23:49 GMT 1/17 event (Event 1 ) recorded at the 3 array stations. This event has an SCSN location of $3420.68 \mathrm{~N} 11839.98 \mathrm{~W}$, a depth of 1.8 $\mathrm{km}$, and a magnitude of 4.0. To obtain a displacement record, the velocity recordings are instrument-corrected, integrated, and high-pass filtered above $0.1 \mathrm{~Hz}$. The integration to displacement emphasizes the longer period signals, for which there is a better coherence across the array.

Because the timing is unreliable at the level of accuracy needed to perform array analysis, we follow the procedure of Hough et al. (1993), aligning the time series so that the first Pwave arrivals have apparent velocities across the array of $2000-2500 \mathrm{~m} / \mathrm{sec}$ and yield the correct back-azimuth to the known epicenter. For each event, the alignments are constrained to be the same for each of the three components. To choose a set of time delays for an event, we first align the time series using a prescribed velocity for the first identifiable sharp Pwave arrival. The delays are further refined using a trial-anderror consideration of results from all three components. Results for the later, slower arrivals are found to be quite insensitive to the assumed P-wave velocity; we will discuss a formal analysis of errors in a later section. The process of aligning the seismograms will obviate a possibly-large source of timing error: possible $\mathrm{P}$-wave site delays due to lateral variations in sediment structure. This procedure is found to yield back-azimuth values that are relatively robust, but absolute velocity values that are less well-determined.

To estimate apparent velocities and azimuths of arrivals, we use a moving-window slowness analysis presented by Frankel et al. (1991). Using the integrated seismograms, cross correlations

$$
C=\frac{\sum\left[x_{1}(t+\delta t) x_{2}(t)\right]}{\sqrt{\sum\left[x_{1}(t+\delta t)^{2}\right] \sum\left[x_{2}(t)^{2}\right]}}
$$



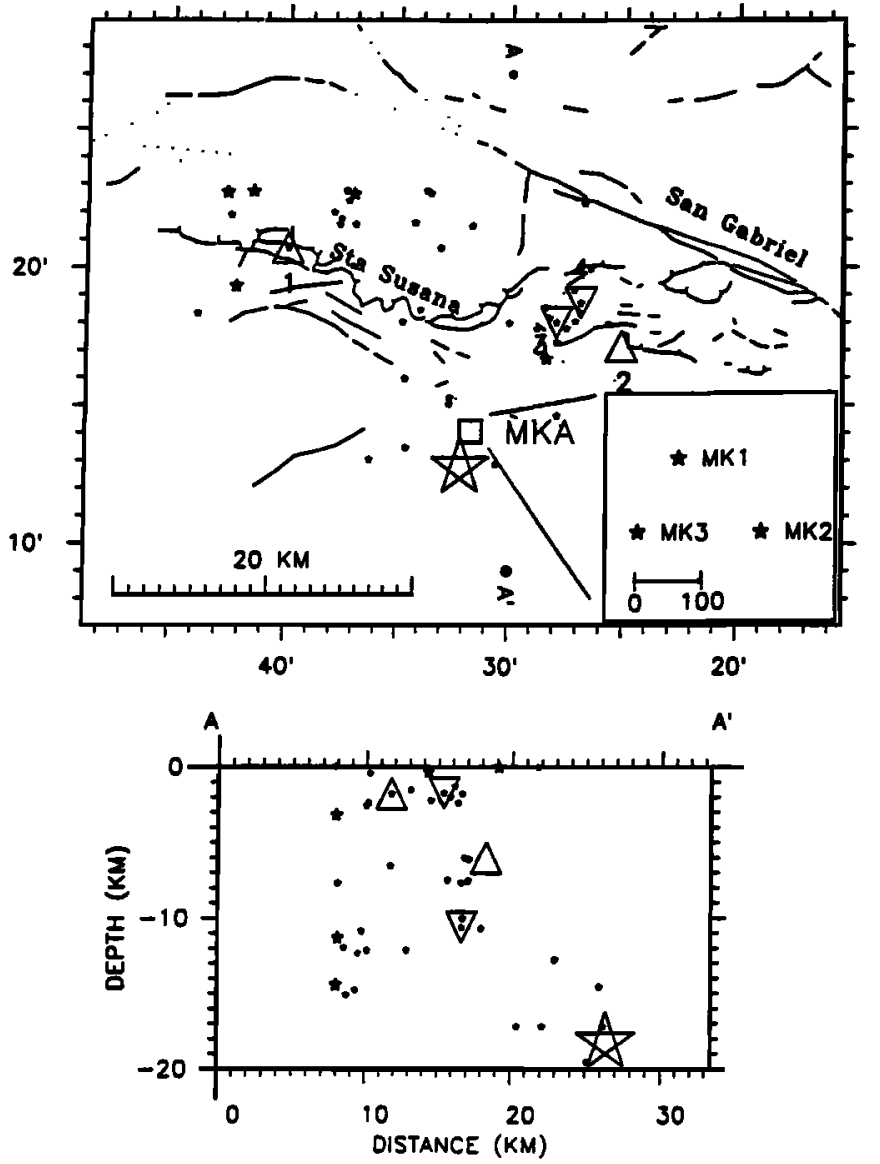

Figure 1. Map of the Northridge region. Large star indicates Northridge mainshock epicenter; small stars show locations of aftershocks recorded through 2/94; square shows location of dense array, with the geometry shown in the inset figure (inset scale indicates $100 \mathrm{~m}$ ). The two upward-pointing triangles indicate the two discussed events (1 and 2$)$ which are inferred to generate surface waves at the Northridge array; the two downward pointing triangles ( 3 and 4 ) indicate the two discussed events that generated simple waveforms with durations that are not prolonged. The traces of the Santa Susana and San Gabriel faults are indicated.

are determined for a range of time delays,

$$
\delta \mathrm{t}=\mathrm{p}_{\mathrm{x}} \delta \mathrm{x}+\mathrm{p}_{\mathrm{y}} \delta \mathrm{y}
$$

where the east-west and north-south slowness, $p_{x}$ and $p_{y}$, vary over a range of values. The average cross correlation is determined for all pairs of stations, and the $p_{x}$ and $p_{y}$ values for a given time window are determined to be those values that give a maximum average cross correlation for all pairs. The apparent velocity across the array is then given by

$$
V=\frac{1}{\sqrt{p_{x}^{2}+p_{y}^{2}}}
$$

and the back azimuth $\phi$ is

$$
\phi=\tan ^{-1}\left(p_{x} / p_{y}\right)
$$

We use 1.0 second windows whose centers are shifted in steps of 0.5 seconds. A 50 by 50 grid of slowness values, corresponding to slowness ranges of $\pm 1 \mathrm{sec} / \mathrm{km}$, (i.e., apparent velocities as low as $707 \mathrm{~m} / \mathrm{sec}$; as low as are reasonably expected) is used. We choose the values of $p_{x}$ and $p_{y}$ that yield the highest average correlations.
The above procedure is repeated for each of the three components. Figure 3 presents the resulting slowness and back azimuth values. Results are not shown for time windows that have an optimal correlation value below a minimum assigned value, in this case 0.6. Low correlation values are found to correlate with unstable results; the limiting correlation value is chosen subjectively, to exclude results that appear to be unstable.

Formal uncertainties can be estimated for the apparent velocity and backazimuth given a specified acceptable level of variance increase above the optimal value. This choice is itself subjective, and the resulting values do not reflect uncertainties from the alignment procedure. These error bars are therefore not considered to be necessarily reflective of the actual uncertainties. For illustration, however, figure 3 presents error bars estimated for the vertical component, representing misfit within $10 \%$ of the optimal value.

The results are observed to be consistent for the three components, each with the following salient characteristics: 1) The apparent velocity for the $P$ wave is slightly higher than that of the $S$ wave; 2 ) There is a sharp drop in apparent velocity after approximately 8 seconds from the start of the record, with later arrivals characterized by velocities in the range $800-1000$ $\mathrm{m} / \mathrm{sec}$; 3) The initial backazimuth is close to the 45-degree backazimuth to the known epicenter, as prescribed by the alignment procedure, but there is a suggestion that later backazimuth values are shifted by 10-20 degrees (i.e., arrive from a more northly azimuth than the northwest backazimuth to the event). Although this last observation is not necessarily significant given the formal error bars, it derives further support from the consistency of results from time windows separated by 1-10 seconds. That is, back-azimuth values inferred for the direct arrivals are systematically lower than those inferred for the later arrivals, with both sets of values showing good internal consistency.

The results listed above are found to be insensitive to the choice of apparent velocity used to align the time series. For

1/17 23:49 Event (NS)

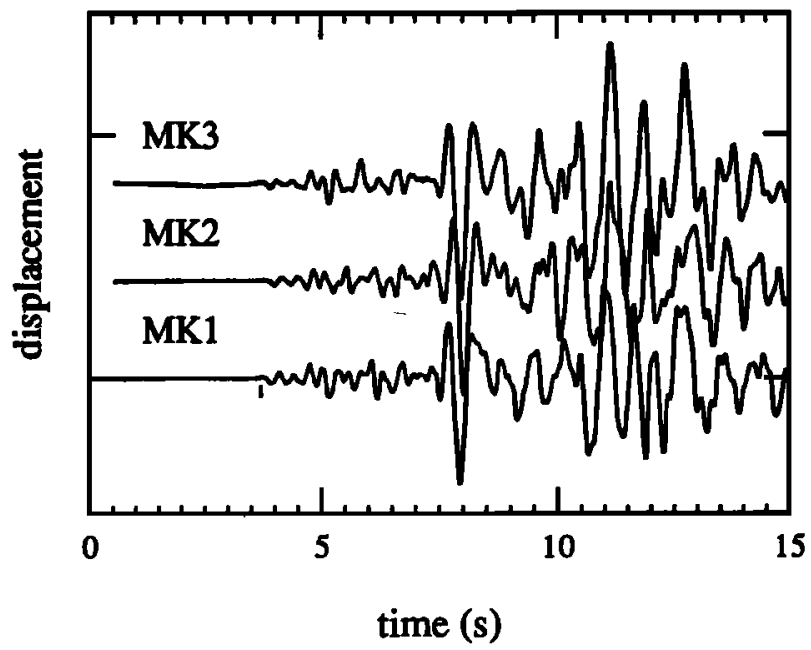

Figure 2. The NS component of ground motion recorded at the three dense array stations, MK1, MK2, and MK3, for the M4.0 event at 23:49 GMT on 1/17/94. Velocity records are integrated and high-pass filtered above $0.1 \mathrm{~Hz}$ to obtain displacement. Records are offset for clarity, and are aligned along the first positive pulse (indicated for MK1) rather than by absolute time. Peak displacement levels corresponding to the MK1 trace are approximately $0.008 \mathrm{~cm}$. 

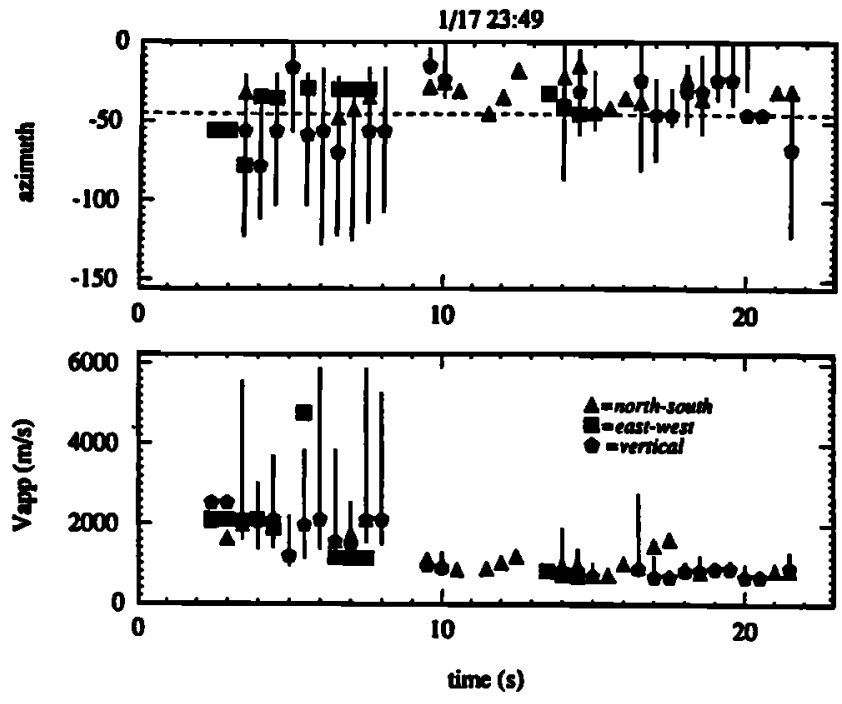

Figure 3. Array results for the 1/17 23:49 event (Event 1). The bottom figure shows the apparent velocity estimated within 0.5 -second subwindows throughout the NS (triangles), EW (squares), and V (pentagons) components of motion, respectively; the top figure shows the inferred back azimuths calculated for the same components and subwindows, with a dashed line showing the back-azimuth to the epicenter.

example, the apparent velocity of the later arrivals is barely affected even if assumed initial velocity is doubled because the direct arrival apparent velocities are so much faster than the later apparent velocities. That is, the change in time delay corresponding to a change from, say, $2.5 \mathrm{~km} / \mathrm{sec}$ to $5 \mathrm{~km} / \mathrm{sec}$, contributes to only a small fraction of the time delay corresponding to a wave with a velocity of $1 \mathrm{~km} / \mathrm{sec}$. This insensitivity is also illustrated by the error bars shown in Figure 3 , which indicate poor resolution of the direct-arrival apparent velocity (i.e., an inferred range of $\approx 1600-5000 \mathrm{~m} / \mathrm{s}$ for most time windows).

We obtain similar results for the M3.4 aftershock that occurred at $3417.15 \mathrm{~N}, 11825.09 \mathrm{~W}$ at $21: 26$ GMT on $1 / 21$ (Event 2). The SCSN depth for this event is listed at $6.0 \mathrm{~km}$, which indicates poor depth control. Like Event 1, this event is observed to be characterized by a prolonged duration of the highest amplitude arrivals. Because this event is smaller and dominated by higher frequency energy, a lower degree of correlation is observed across the array. However, the array analysis shows that the later, large-amplitude arrivals from this event are also characterized by low apparent velocities, and also suggest that some of the later energy is arriving significantly offazimuth, from the far (west) side of the valley relative to the source location.

Figure 4 contrasts the NS component of the M3.4 event discussed above with the NS component for two other events: a M4.7 event that occurred at 18:39 on 1/21 (Event 3) an a M4.0 event that occurred at 19:35 on 1/17 (Event 4). Both events have similar location to Event 2 (Figure 1). The waveform recording for these two events appears to have a similar period content to events 1 and 2 , but to be qualitatively different in character from those discussed in earlier sections: they are characterized by a fairly simple, sharp displacement pulses, with a durations that are not anomalous. Neither type of event is observed to be unique within the data set. In Figure 1, we show the locations of the 4 events discussed in this paper. From this figure, and from an examination of other events not dis- cussed here, we note that events well to the north of the San Fernando Valley all have prolonged durations, while those events with simple waveforms generally have locations that lie within the perimeter of (that is, generally beneath) of the San Fernando Valley (in the vicinity of Events 2-4, the northern edge of the valley corresponds with the trace of the Santa Susana fault). We consider it unlikely that the two classes of events simply reflect differences in event depths. While source depths are notoriously uncertain, there is no reason why events occurring within and under the basin would be particularly biased towards apparent shallow depths.

\section{Discussion and Conclusions}

For events 1 and 2, the decrease in apparent velocity after the direct arrivals is similar to what has been observed in other valleys (e.g., Frankel et al., 1991; Hough et al., 1993), and is inferred to indicate the end of direct arrivals from the fault and the beginning of converted surface-wave arrivals trapped within the valley. The apparent velocities of the inferred surface wave arrivals cluster around $900 \mathrm{~m} / \mathrm{sec}$; although there is some uncertainty associated with the determination of this absolute velocity, the results require that the apparent velocity of the later arrivals be substantially slower than the direct P- and S-wave arrivals, and slower than would be expected for deeper crustal
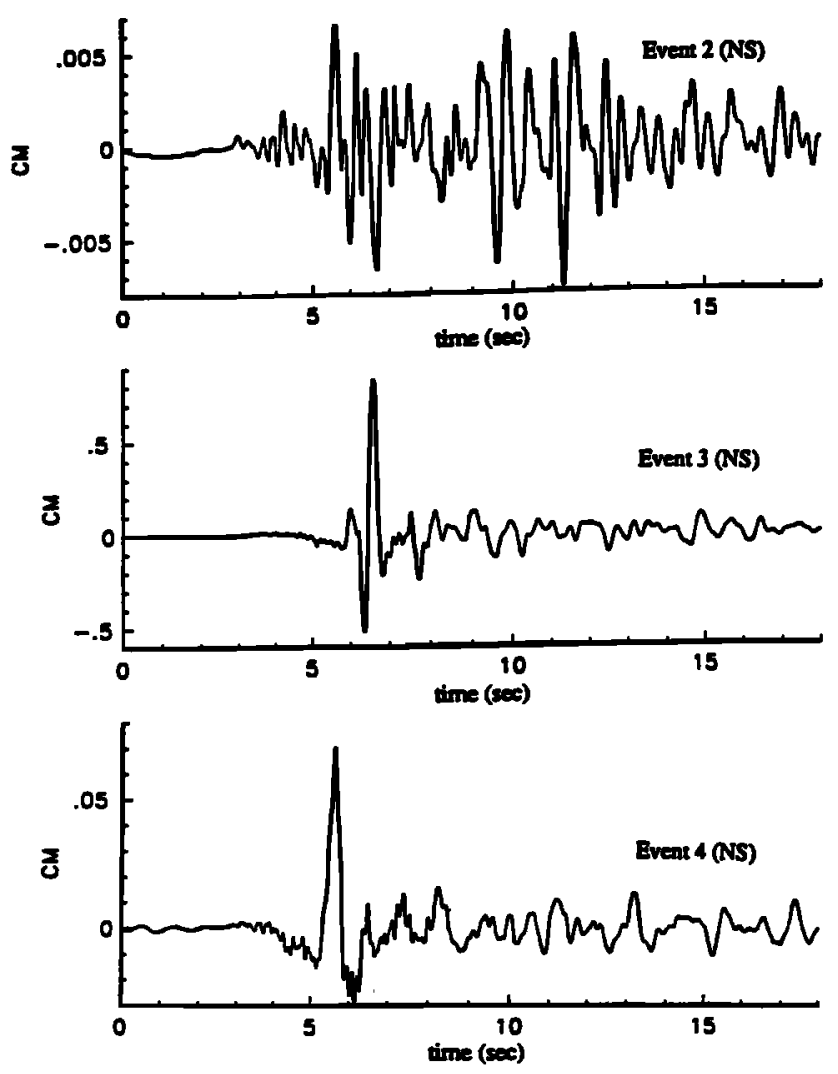

Figure 4. The top figures shows the NS component of the M3.4 event at 21:26 GMT on 1/21/94 (Event 2); the middle and bottom figures show the NS component from a M4.7 event that occurred at 18:39GMT on $1 / 21 / 94$ (Event 3) and a M4.0 event that occurred at 19:35GMT on 1/17/94 (Event 4). All records show displacement, obtained by twice-integrating the fba recordings. The records are highpass filtered above $0.3 \mathrm{~Hz}$ following the integration. The top two events have epicenters within a few $\mathrm{km}$ of each other. 
surface waves (e.g.. Bullen, 1963). The results also suggest that the later arrivals arrive slightly off azimuth. Based on the similarity to studies referenced above, and the inferred apparent velocities for the later arrivals, we conclude that the prolonged durations of some Northridge aftershocks are also caused by converted surface waves generated within the San Fernando Valley.

Our results are generally consistent with those of Vidale and Helmberger (1988), who used a 2-D finite-difference approach to model strong ground motions from the 1971 San Fernando earthquake, and Frankel and Vidale (1992) who model ground motions in the San Bernardino basin. These studies also concludes that converted surface waves comprise a significant component of the recorded ground motions across the valley. They use basin S-wave velocities of $600-1100 \mathrm{~m} / \mathrm{sec}$; generally consistent with the inferred apparent surface wave velocity determined in this study.

Unlike previous observational studies that have provided evidence for converted surface waves in valleys or basins, the Northridge aftershock sequence provides sources that are very close, in some cases within, the San Fernando Valley. Our waveform observations demonstrate significant variability of waveform character at a given site; these differences suggest that the efficiency with which the converted surface waves are created may depend critically on the locations of the source and receiver.

Although the generation of converted surface waves is complex, we briefly consider a few simple theoretical considerations that may bear on the sensitivity of surface wave generation to source location with respect to the valley. As discussed by Bullen (1963), incident P/SV energy will reflect from the free surface primarily as SV waves for a fairly wide range of incident angles, roughly $2-60^{\circ}$, while incident $P$ waves will reflect primarily as $\mathbf{P}$ for nearly vertical incidence. Calculations of horizontal eigenfunctions for Rayleigh waves in a layered half-space also show that the P/SV ratio is generally less than 1 (e.g., Aki and Richards, 1980). Thus, it is plausible that arrivals at some valley sites will be steeply-incident body waves that have not generated enough SV energy to efficiently generate Rayleigh waves. (These same events may well generate surface waves at other sites within the valley, however). A second possible consideration is that the conversion of body waves to surface waves requires a slowing of the horizontal phase velocity by the down-dip basin/basement interface; the phase velocity of a wave traveling up-dip will increase.

In Southern California especially, numerous major faults run along the base of mountains, next to basins in which denselypopulated cities have developed. Examples include the Sierra Madre fault system at the base of the San Gabriel Mountains and the San Andreas Fault at the base of the San Bernardino Mountains. The results of this study (and previous studies) show that converted surface waves within basins will be an important factor in controlling earthquake ground motions. The results from this study suggest that the prediction of ground motions from future events, while ultimately tractable, need to consider carefully the location of the source.

Acknowledgments. We thank the Diaz, Siebert, and Peterson families of Northridge for graciously allowing us to use their backyards for our array deployment; we thank Dave Wald for his assistance in the field the morning of January 17, and we thank Art Frankel, Joan Gomberg, and Paul Richards for helpful discussions. We thank John Vidale, Bill Ellsworth, Harold Magistrale, and three anonymous reviewers for their reviews of the manuscript.

\section{References}

Aki, K., and P.G. Richards, Quantitative Seismology, W.H. Freeman and Co., San Francisco, 1980.

Borcherdt, R.G., J.B. Fletcher, E.G. Jensen, L. Maxwell, J.R. Van Shaak, R.E. Warrickm, E. Cranswick, J.S. Johnston, and $\mathrm{R}$. McClearn. A general earthquake-observation system, Bull. Seism. Soc. Am., 75, 1783-1825, 1985.

Bullen, K.E. An introduction to the theory of seismology, 3rd ed., Cambridge University Press, Cambridge, England, 1963.

Frankel, A., S. Hough, P. Friberg, and R. Busby. Observations of Loma Prieta Aftershocks from a dense array in Sunnyvale, California, Bull. Seism. Soc. Am. 74, 1900-1922, 1991.

Frankel, A. and J. Vidale. A Three-Dimensional Simulation of Seismic Waves in the Santa Clara Valley, California, From a Loma Prieta Aftershock, Bull. Seism. Soc. Am. 82, 2045 2074, 1992.

Hough, S.E., J. Mori, E. Sembera, G. Glassmoyer, C. Mueller, and S. Lydeen Southern surface rupture associated with the 1992 M7.4 Landers earthquake: did it all happen during the mainshock? Geophys. Res. Lett., 20, 2615-2618, 1993.

Vidale, J.E. and D.V. Helmberger, Elastic finite-difference modeling of the 1971 San Fernando, California, earthquake, Bull. Seism. Soc. Am. 78, 122,141, 1988.

S. Hough, U.S. Geological Survey, Pasadena, CA 91106

E. Sembera, G. Glassmoyer, C. Mueller, U.S. Geological Survey, Menlo Park, CA 94035

(Received: June 7, 1994; revised: September 19, 1994; accepted: December 9, 1994) 